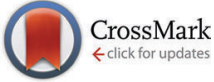

Cite this: Mol. BioSyst., 2015, 11, 2808

Received 6th May 2015, Accepted 12th August 2015

DOI: 10.1039/c5mb00319a

www.rsc.org/molecularbiosystems

\title{
The transcriptome of Euglena gracilis reveals unexpected metabolic capabilities for carbohydrate and natural product biochemistry $\dagger$
}

\author{
Ellis C. O’Neill, ${ }^{a}$ Martin Trick, ${ }^{b}$ Lionel Hill, ${ }^{c}$ Martin Rejzek, ${ }^{a}$ Renata G. Dusi, ${ }^{d}$ \\ Chris J. Hamilton, ${ }^{d}$ Paul V. Zimba, ${ }^{e}$ Bernard Henrissat ${ }^{f g h}$ and Robert A. Field*a
}

\begin{abstract}
Euglena gracilis is a highly complex alga belonging to the green plant line that shows characteristics of both plants and animals, while in evolutionary terms it is most closely related to the protozoan parasites Trypanosoma and Leishmania. This well-studied organism has long been known as a rich source of vitamins $A, C$ and $E$, as well as amino acids that are essential for the human diet. Here we present de novo transcriptome sequencing and preliminary analysis, providing a basis for the molecular and functional genomics studies that will be required to direct metabolic engineering efforts aimed at enhancing the quality and quantity of high value products from E. gracilis. The transcriptome contains over 30000 protein-encoding genes, supporting metabolic pathways for lipids, amino acids, carbohydrates and vitamins, along with capabilities for polyketide and non-ribosomal peptide biosynthesis. The metabolic and environmental robustness of Euglena is supported by a substantial capacity for responding to biotic and abiotic stress: it has the capacity to deploy three separate pathways for vitamin C (ascorbate) production, as well as producing vitamin $\mathrm{E}$ ( $\alpha$-tocopherol) and, in addition to glutathione, the redox-active thiols nor-trypanothione and ovothiol.
\end{abstract}

\section{Introduction}

Euglenoids are abundant algae, typically found in freshwater rich in organics, where they can be so populous as to give their characteristic colour to the water, such as the verdant green Euglena viridis or blood red Euglena sanguinea. They were first documented $^{1}$ by van Leeuwenhoek in his 1674 letter to the Royal Society, ${ }^{2}$ although Harris is usually credited with the first

${ }^{a}$ Department of Biological Chemistry, John Innes Centre, Norwich Research Park, Norwich, NR4 7UH, UK. E-mail: rob.field@jic.ac.uk

${ }^{b}$ Computational and Systems Biology, John Innes Centre, Norwich Research Park, Norwich, NR4 $7 U H, U K$

${ }^{c}$ Department of Metabolic Biology, John Innes Centre, Norwich Research Park, Norwich, NR4 7UH, UK

${ }^{d}$ School of Pharmacy, University of East Anglia, Norwich Research Park, Norwich, NR4 $7 T$, UK

${ }^{e}$ Center for Coastal Studies, Texas A\&M University-Corpus Christi, 6300 Ocean Drive, Unit 5866, Corpus Christi, Texas 78412, USA

${ }^{f}$ Aix-Marseille University, Architecture et Fonction des Macromolécules Biologiques, 163 Avenue de Luminy, 13288 Marseille, France

${ }^{g}$ Centre National de la Recherche Scientifique, UMR 7257, 163 Avenue de Luminy, 13288 Marseille, France

${ }^{h}$ Department of Biological Sciences, King Abdulaziz University, Jeddah, Saudi Arabia

$\dagger$ Electronic supplementary information (ESI) available. See DOI: 10.1039/ c5mb00319a description of this species. ${ }^{3}$ These large unicellular organisms (Fig. 1A), up to $100 \mu \mathrm{m}$ in length, possess an eye spot photoreceptor, enabling Euglena to perceive light and swim towards it using its single flagellum for motility or by a unique so-called euglenoid locomotion. Euglena exhibits mixotrophy, switching between photosynthesis, absorbing nutrients/small metabolites, and engulfing other eukaryotes and bacteria as the opportunity or need arises.

Euglena gracilis has been extensively investigated for the production of vitamins $\mathrm{A}, \mathrm{C}, \mathrm{E},{ }^{4}$ and essential amino acids and is also a good source of polyunsaturated fatty acids. ${ }^{5}$ Although a photosynthetic organism, Euglena does not produce a typical $\alpha-1,4 / 6$-glucan, such as starch. Instead, when grown aerobically in light it produces an insoluble $\beta-1,3$-glucan, paramylon, ${ }^{6}$ contributing up to $c a$. $85 \%$ of its' dry weight. This glycopolymer shows immune stimulatory properties ${ }^{7}$ and is reported to have anti-HIV ${ }^{8}$ effects. In contrast, under anaerobic conditions wax esters ${ }^{9,10}$ comprise over $50 \%$ of the dry weight of some strains of Euglena. These compounds are produced even under adverse conditions such as those encountered in acid mine drains, ${ }^{11}$ which suggests potential for the use of this taxa in waste water management ${ }^{12}$ and/or the production of biodiesel. Euglenoids are physiologically very flexible, resulting in their use in many diverse scientific fields, including: as a reporter for vitamin $\mathrm{B} 12$ production ${ }^{13}$ and for the clinical 

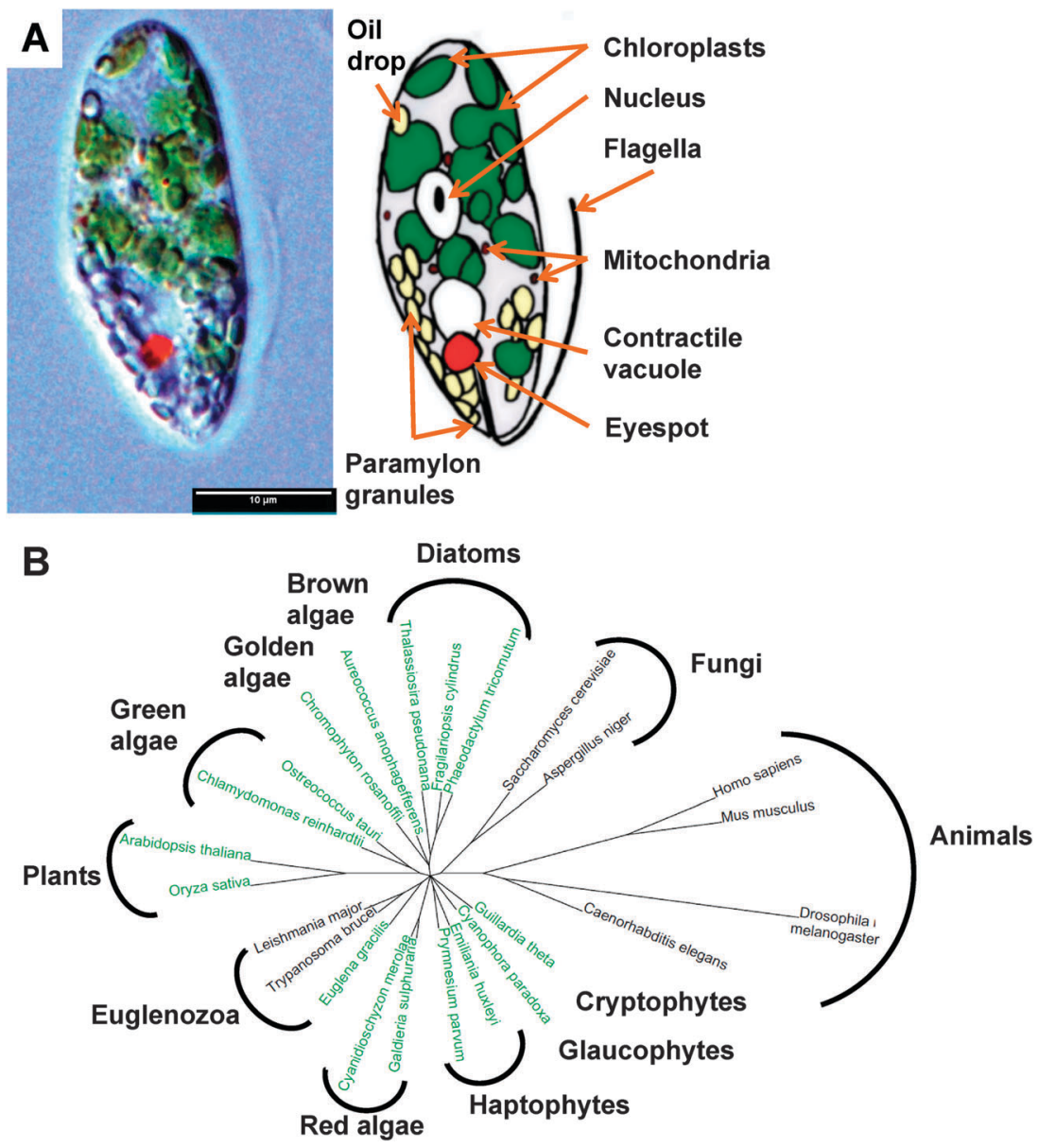

Fig. 1 The biology of Euglena gracilis. (A) Physiology of Euglena gracillis. (B) Phylogeny showing relationship between Euglena gracilis and sequenced algae and model organisms. ${ }^{112}$ Organisms shown in green are photosynthetic.

analysis of B12 in human serum; ${ }^{14}$ to study the ecotoxicity of zinc oxide nanoparticles; ${ }^{15}$ in a neurocomputer based on their motion in a micro aquarium; ${ }^{16}$ and for the intracellular biosynthesis of ferri-hydrite ${ }^{17}$ and silver ${ }^{18}$ nanoparticles. Euglena behaviour has been studied using zero gravity flight ${ }^{19}$ and the nature of their active gravitaxis mechanisms has been investigated under varying acceleration conditions aboard the space shuttle Columbia. ${ }^{20}$

Phylogenetically, Euglena are unlike other rigorously studied algae in that their closest neighbours are the human pathogenic protozoa Trypanosoma and Leishmania (Fig. 1B). Their unique phylogenetic position and the ease with which Euglena can be cultured has made them one of the most highly studied eukaryotes, playing a pivotal role in the development of cell biology and biochemistry, a topic that is thoroughly reviewed in The Biology of Euglena by Buetow ${ }^{21-24}$ and A Color Atlas of Photosynthetic Euglenoids by Ciugulea and Triemer. ${ }^{25}$ However, despite the wellestablished potential for biotechnology applications for euglenoids, we know little about their genetically-encoded metabolic capacity. Sequencing the genome of Euglena has proved problematic due to its size and complexity, which has arisen from a series of endosymbiotic events during its evolution. ${ }^{26,27}$ Aside from typical eukaryotic epigenetic modifications, including DNA methylation and histone acetylation, the genome of Euglena also contains the modified nucleotide Base J (glucosylated hydroxythymidine), also found in kinetoplastids ${ }^{28}$ which complicates DNA sequencing. Additionally Euglena has the ability to extensively process mRNA during transcription, ${ }^{29}$ altering the sequences before translation; hence the proteome would be difficult to predict from its genome. Avoiding the complications of algal genome sequencing ${ }^{30}$ and in order to begin to explore the full metabolic capability of Euglena, we have sequenced the transcriptome of Euglena gracilis var. saccharophila. Transcriptomic approaches are proving increasingly useful for illuminating the functional diversity of microbial eukaryotic life, for instance in the oceans. ${ }^{31}$ Here we present an initial analysis of Euglena transcriptomes obtained from dark and light grown cells, with an emphasis on genes encoding carbohydrate and natural products biochemistry, serving to illustrate the versatile metabolic capacity of this species.

\section{Results and discussion}

Nucleic acid extraction and transcript sequencing

To obtain a broad set of transcripts, RNA was extracted from Euglena gracilis cells grown under two radically different growth 
Table 1 Summary of Euglena gracilis transcriptome

\begin{tabular}{|c|c|c|c|}
\hline & Light-grown cells & Dark-grown cells & Combined \\
\hline Total number of nucleotides & $26.5 \mathrm{~Gb}$ & $11.9 \mathrm{~Gb}$ & $38.4 \mathrm{~Gb}$ \\
\hline Total number of contigs & 233748 & 231176 & \\
\hline Total number of predicted ORFs longer than 100 aa & 45126 & 47607 & 92733 \\
\hline Number of unique proteins & $22814^{a}$ & $26738^{a}$ & $32128^{a}$ \\
\hline Mean length of unique proteins & 456 aа & 401 aa & \\
\hline
\end{tabular}

conditions. For autotrophic (photosynthetic) growth, cells were cultured under ambient illumination on low nutrient media solid agar, containing no amino acids or carbon source (referred to as "light"); high nutrient media liquid culture, containing glucose and amino acids with no light source (referred to as "dark"), was used to stimulate mixotrophic growth. Equal amounts of mRNA from these two conditions were sequenced using an Illumina HiSeq 2000 to give $26.5 \mathrm{~Gb}$ and $11.9 \mathrm{~Gb}$ of good quality reads for light and dark grown cells, respectively (Table 1). These sequences were assembled into contigs and likely coding regions were predicted using the Trinity software package. ${ }^{32}$ In this manner, 22814 predicted protein-encoding genes were identified in light-grown cells, while 26738 were evident in dark-grown cells, accounting for 32128 non-redundant proteins predicted overall. This indicates that, depending on growth conditions, there is a dramatic shift in metabolic capability.

Various eukaryotes splice a short leader sequence onto the $5^{\prime}$ end of the mRNA, encoded from a different region of the genome, to process the polycistronic transcripts and stabilise the produced mRNAs. ${ }^{33}$ Previously a 26 nucleotide short leader sequence had been identified in Euglena from 4 sequences, ${ }^{34}$ but this sequence was present in $<1 \%$ of the transcripts presented here. However a reduced 14 base sequence, "TCTATTTTTTTTCGA", was present at the $5^{\prime}$ UTR of $16.0 \%$ and $15.6 \%$ of the transcripts from light and dark grown cells, though it is unclear how many sequences without this modification are in fact full length, rather than truncated by limitations of the sequencing.

In order to annotate gene functions, the 32128 sequences were compared to the UNiRef 100 database using BLASTP, which produced 14389 matches to proteins with annotated functions. $\$$ The majority of transcript sequences identified therefore show no match to any previously reported protein sequence from any organism. Of the sequences that can be annotated, 12020 were classified into 157 Gene Ontology classifications, covering the full spectrum of functions that one might expect in a complex eukaryotic organism (Fig. 2). The distribution of the top BLASTP hits shows a distribution across the kingdoms of life, highlighting the diversity of possible origins of genetic material present in the Euglena

\# It should be noted that whilst some Euglena gracilis sequences already available in the databases match the transcripts presented here, many do not. This is likely due to the strains used in other studies not being related to the one used in the present study: caution should be taken when comparing sequence data from different algal isolates. genome, which have been integrated through its complex phenotypic and genotypic history. ${ }^{27}$

\section{Metabolism}

Candidate genes were identified in the Euglena transcriptome for all of the core metabolic pathways, including glycolysis and gluconeogenesis, the citric acid cycle and the pentose phosphate pathway. There are also candidates for carotenoid and thylakoid glycolipid biosynthesis, and the Calvin cycle, which are required for photosynthesis. Reassuringly, the completeness of these pathways confirms both adequate sequencing depth and accurate functional assignments.

In addition to the expected candidates for fatty acid biosynthesis, a capacity to produce isoprenoids, which have functions in primary metabolism, is also evident in the Euglena transcriptome. There are two pathways for the formation of the isoprenoid precursor in plants: the cytosolic mevalonate (MVA) ${ }^{35}$ and the plastidial methyl erythritol phosphate (MEP) pathway. ${ }^{36}$ Both pathways are known in Euglena, although unusually the MEP pathway only contributes to carotenoid biosynthesis and is not involved in phytol synthesis. ${ }^{37}$ All enzymes for both pathways can readily be identified in the transcriptome, with the exception of the final decarboxylase of the MVA pathway (Fig. 3). The presence of the rest of the pathway in Euglena implies this last reaction is likely catalysed by a non-canonical enzyme. The initial and final enzymes for the chloroplast-localised MEP pathway are only apparent in the transcripts from dark grown cells, suggesting that under the conditions utilised in this study, the MEP pathway is only active in chloroplasts that are not supplying energy to the cells.

Euglena is self-contained in its amino acid requirements, producing transcripts of all the obvious genes required for the production of this class of molecule. Intriguingly, however, Euglena appears to have acquired and retained genes for amino acid biosynthesis that are reminiscent of both plant and bacterial pathways. Moreover, it appears to duplicate functionality in places: for aromatic amino acid biosynthesis, for instance, transcripts for single function enzymes are evident alongside much larger transcripts encoding several steps in the pathway (Fig. S1, ESI $\dagger$ ). ${ }^{27}$ The ability to produce multi-functional polydomain proteins, arising from gene fusions, presents interesting opportunities from a synthetic biology perspective.

\section{Carbohydrate-active enzymes}

Euglena is not reported to have a carbohydrate-based cell wall but it is known to utilise a $\beta-1,3$-glucan carbohydrate storage 
A

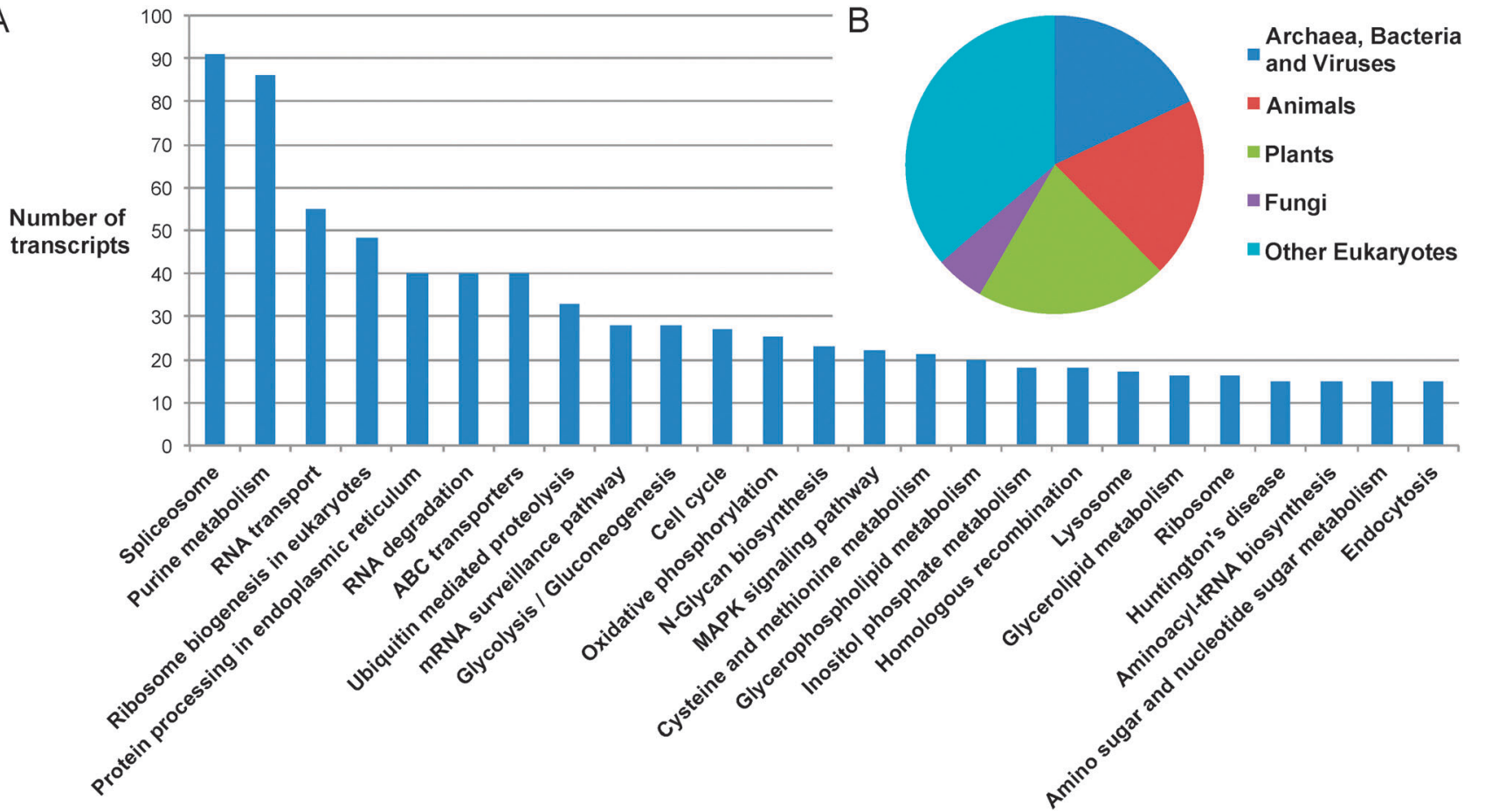

Fig. 2 Assignment of transcripts. (A) Top 25 Gene Ontology terms assigned to the transcriptome. (B) Kingdom-level taxonomic distribution of top hits of BLAST matches ( $E$-values $\left.<1 \times 10^{-10}\right)$ of $E$. gracilis unique sequences.

polymer and it can become encased in a carbohydrate sheath, forming cysts. ${ }^{38}$ Although the exact nature of the surface glycan(s) is not known, it is thought to be highly complex, containing glucose, galactose, mannose, fucose, xylose, rhamnose and at least one hexosamine. ${ }^{39}$ The anticipated variety of glycans and the metabolic versatility displayed by Euglena make this a potentially attractive organism in which to study carbohydrate metabolism. This notion is supported by the wealth of carbohydrate-active enzymes that are evident from transcriptome data (Table 2).

With around 230 glycosyltransferases (GTs) (depending upon the stringency used in annotation), Euglena is rich in GTs like Homo sapiens or Caenorhabditis elegans and much richer than the red alga Porphyridium purpureum, the green algae Micromonas sp, the basal alga Cyanophora paradoxa, the cryptophyte Guillardia theta and the chlorarachniophyte Bigelowiella natans (data from the CAZy database ${ }^{40}$ ). Viridiplantae ('green plants') have significantly more GTs than Euglena, and this is attributable to several rounds of genome duplication. A repertoire of around 130 glycosyl hydrolases, dominated by enzymes for the digestion of $\beta$-glucans (vide infra), and very few different carbohydrate-binding modules (CBMs), underlies a modest commitment to glycan digestion which may reflect the photosynthetic nature of this organism, which enables it to be largely self-sufficient in terms of carbohydrate metabolism.

$\boldsymbol{\beta}$-1,3-Glucan metabolism. The storage polysaccharide in E. gracilis, paramylon, is composed of $\beta$-1,3-linked glucose, rather than the more common $\alpha$-1,4-linked glucan found in plants, animals and bacteria. Paramylon is a crystalline granule which is found in the cytosol, with characteristic shape dependent upon the species of Euglena. ${ }^{41}$ These granules are synthesised by transfer of glucose from UDP-glucose by paramylon synthase (Fig. 4), a membrane bound $670 \mathrm{kDa}$ complex composed of at least 7 different proteins. ${ }^{42}$ Interestingly paramylon synthesis appears to commence with the auto-glucosylation of a protein, in a similar way to glycogen but not starch biosynthesis. ${ }^{43}$ In order to identify the likely proteins involved in paramylon metabolism, transcripts encoding potential $\beta$-glucan-active enzymes were identified and annotated (Fig. 4).

Plants and fungi synthesise the $\beta$-1,3-glucans in their cell walls using membrane-bound members of the GT48 family, which may represent candidate paramylon synthases in Euglena. Four sequences could be identified in the transcriptome which encode candidate GT48 $\beta$-1,3-glucan synthases, three of which are closely related to each other ( $94 \%$ identity). These proteins are predicted to be around $300 \mathrm{kDa}$ in size much larger than the proteins reported to make up the paramylon synthase complex, ${ }^{42}$ although proteolytic processing cannot be ruled out. Enzymes of the GT2 family can also participate in the biosynthesis of $\beta-1,3-$ and $\beta-1,4$-glycans, such as callose, chitin, and cellulose ${ }^{40}$ and thus also represent potential candidates for paramylon synthase. This family is heavily represented in the Euglena transcriptome, with 16 unique members, although few of these proteins has the QXXRW signature of processive polysaccharide synthases. ${ }^{44}$

Both endo- and exo- $\beta-1,3$-glucan hydrolases have been biochemically identified in Euglena, ${ }^{45,46}$ and there are many glycoside hydrolases present in the Euglena transcriptome that belong to the various GH families capable of degrading $\beta-1,3-$ glucans. There are transcripts encoding 17 members of family 


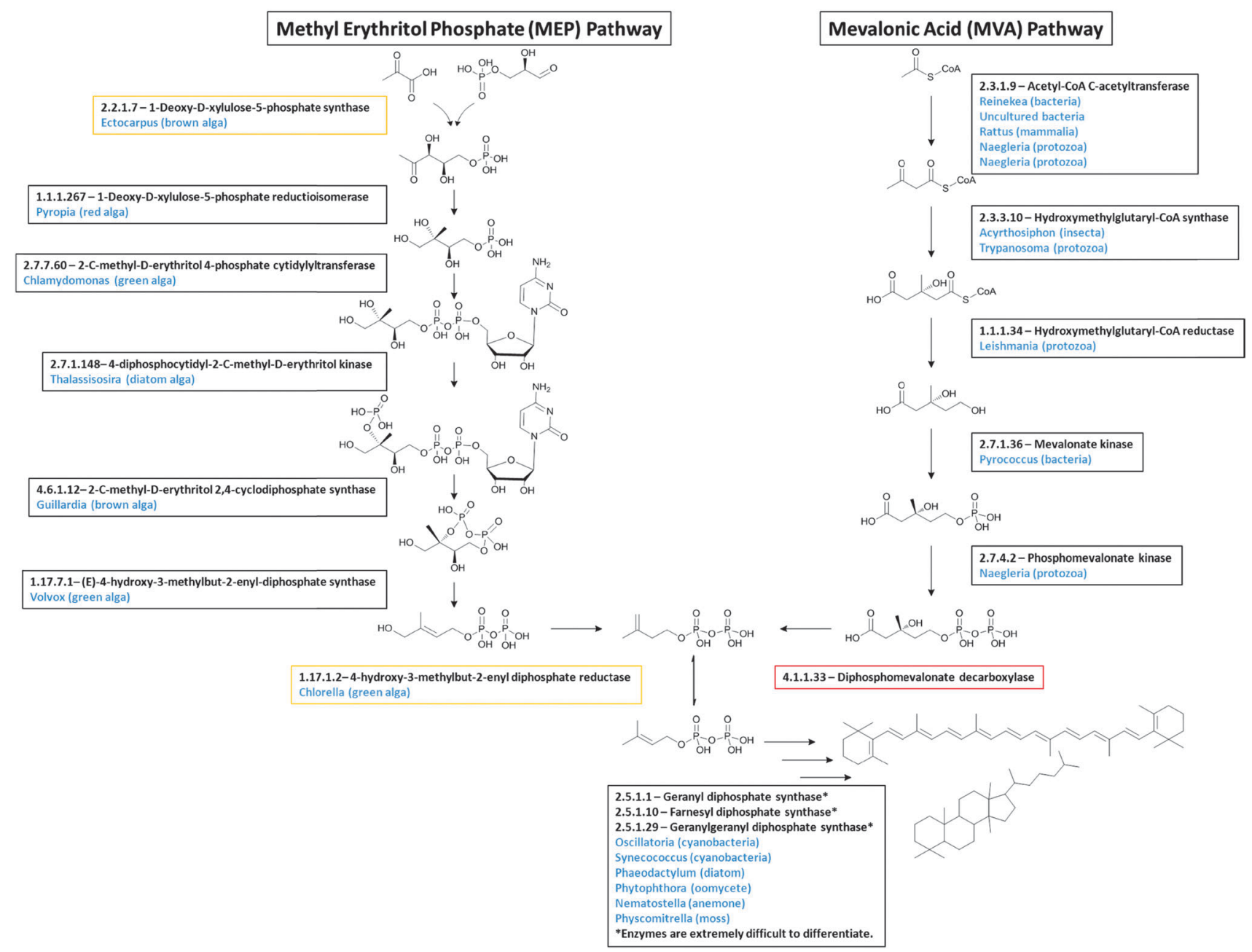

Fig. 3 The isoprenoid biosynthetic pathways. There was no isoform for the final decarboxylase of the MEP pathway indicating an alternative enzyme must be used in Euglena. In blue below each enzyme is the genus of the closest relative found for each isoform in the NCBI non-redundant protein sequences collection, using BLASTP. The yellow boxes indicate the Euglena sequences could only be found in the transcriptome from dark grown cells; red boxes indicate no homologues could be found in either the dark or light transcriptome.

Table 2 Annotation of carbohydrate active enzymes in Euglena transcriptome ${ }^{a}$

\begin{tabular}{llc}
\hline Family & Proteins & Families \\
\hline Glycosyl transferases (GTs) & 229 & 34 \\
Glycoside hydrolases (GHs) & 126 & 26 \\
Carbohydrate binding modules (CBM) & $2(+2$ on GHs) & 4 \\
Carbohydrate esterases & 9 & 2
\end{tabular}

${ }^{a}$ For a full breakdown of the carbohydrate active enzymes in Euglena gracilis see http://www.cazy.org/eE.html.

GH81, as well as three members of family GH17 and a single member of family $\mathrm{GH} 64$, all families which contain endo-acting hydrolases capable of cleaving in the middle of $\beta$-1,3-glucan chains. These enzymes release short glucan chains which could then be further degraded to glucose by $\beta$-glucosidases, for which there are sequences for members of 6 families (GH1, 2, $3,5,30,55)$ in the Euglena transcriptome. Alternatively, glucans could be degraded by phosphorylases, ${ }^{47}$ releasing Glc-1-P. $\beta-1,3$-Glucan phosphorylases have been well characterised in
Euglena $^{48,49}$ and other unrelated algae, ${ }^{50}$ and have since been identified in bacteria. ${ }^{51,52}$ The bacterial enzymes are in family GH94 but exclusively act upon the disaccharide, laminaribiose. No members of this family are present in the transcriptome, suggesting Euglena utilises another enzyme family for this activity.

Proteins and glycans. Protein glycosylation is one of the hallmarks of eukaryotic cells, but has also been found in some bacteria. ${ }^{53}$ The biosynthesis of asparagine-linked glycans ( $N$-glycans) proceeds by the synthesis of a lipid linked oligosaccharide precursor, which is transferred en bloc to proteins in the lumen of the endoplasmic reticulum. ${ }^{54}$ Euglena has been demonstrated to make the same precursor oligosaccharide as animals and fungi $\left(\mathrm{Glc}_{3} \mathrm{Man}_{9} \mathrm{GlcNAc}_{2}\right.$-Asn $){ }^{55}$ whilst the related Trypanosomes have lost the ability to glucosylate the precursor and Leishmania add two fewer mannose residues. ${ }^{56}$ Flagellaassociated glycoproteins in Euglena are affected by tunicamycin, a known inhibitor of protein glycosylation, ${ }^{57}$ but the exact structure of the glycans and the identity of glycosylated proteins 

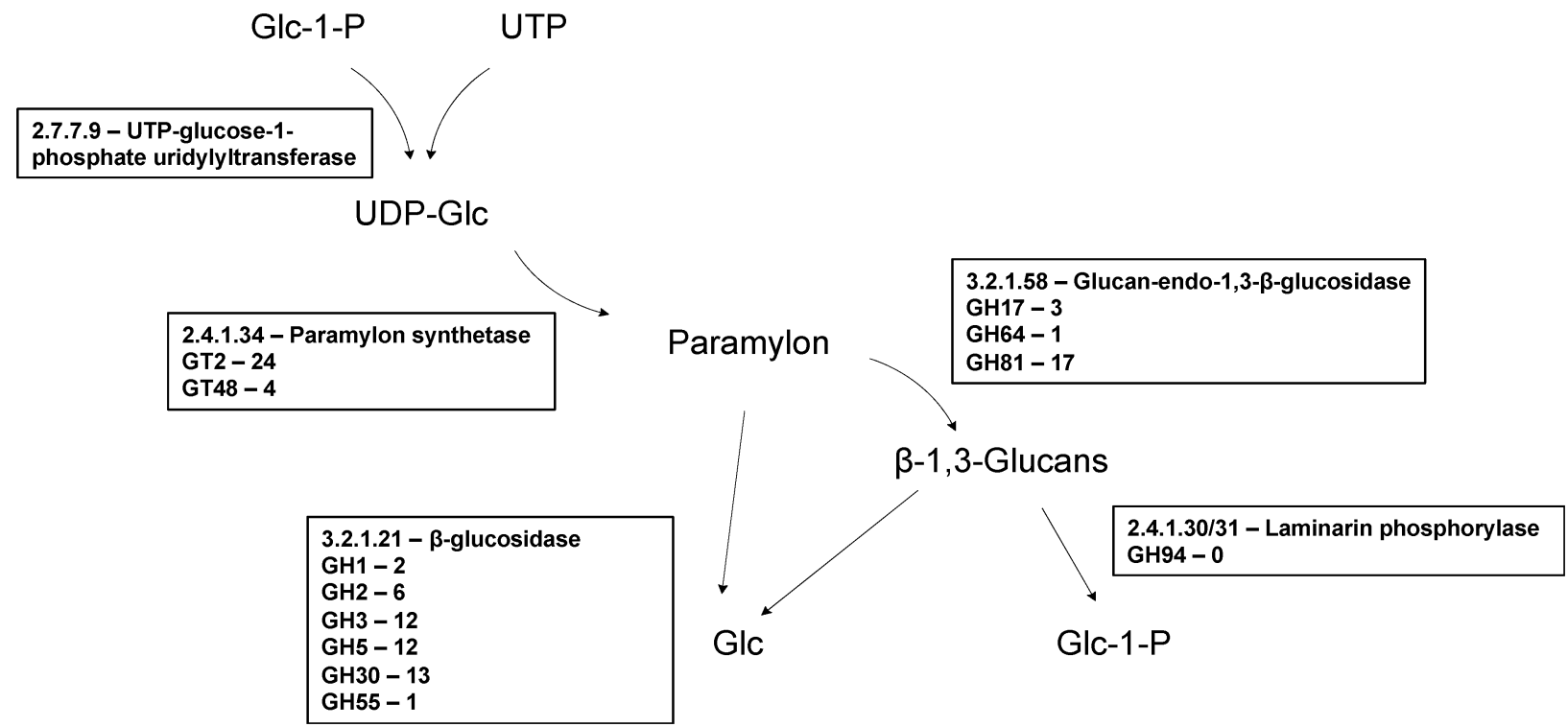

Fig. 4 Enzymes proposed to be involved in paramylon biosynthesis. In Euglena paramylon is synthesised by glucosyl transfer from UDP-glucose, initially onto a membrane bound protein, ${ }^{113}$ by a protein complex, forming strictly linear $\beta$-1,3-glucan chains which form intra chain triple helices. In plants and fungi members of GT48 and GT2 are used to make $\beta-1,3$-glucans and members of both are present in the transcriptome. Paramylon is degraded by a series of endo- and exo- $\beta$-glucosidases to form glucose, ${ }^{114}$ or by laminarin phosphorylase to form $\alpha$-glucose-1-P. ${ }^{115}$ There are many members of $\beta$-glucosidase families in the transcriptome but there is no member of GH94, the family to which the only sequenced laminaribiose phosphorylases belong, ${ }^{51}$ suggesting a novel family for this activity in Euglena.

remain elusive. Sequences for all of the enzymes required for synthesising the full $\mathrm{Glc}_{3} \mathrm{Man}_{9} \mathrm{GlcNAc}_{2} \mathrm{~N}$-glycan precursor are present in the Euglena transcriptome, along with three sequences for the GT66 oligosaccharyltransferases that couple the pre-formed oligosaccharide to proteins (Table S1, ESI $\dagger$ ).

Euglena has a full complement of genes for the biosynthesis of glycosylphosphatidylinositol (GPI) membrane anchors. This is perhaps unsurprising for an organism that is phylogenetically related to the Trypanosomes, which make extensive use of such glycolipids to attach proteins to their surface, (Table S2, ESI $\dagger$ ). However, this class of compounds remains to be identified and characterised in Euglena species; it is unclear whether the prevalent use of GPI biochemistry in the parasitic protozoa, with a need to rapidly alter their surface coat in order to evade the host immune response, is replicated in their rather benign water-borne relatives.

Xylose-containing polysaccharide metabolism. Although it does not contain a classical plant-like polysaccharide cell wall, it has been reported that Euglena has a complex xylosecontaining material associated with its flagella, ${ }^{58}$ the precise structure of which has not been elucidated. A UDP-glucuronate decarboxylase, responsible for the synthesis of the activated xylose building block UDP-xylose, has been identified in Euglena previously ${ }^{59}$ and there is one obvious transcript encoding this enzyme in the Euglena transcriptome. Many enzymes related to characterised xylosyltransferases are also represented in the transcriptome, in particular 16 members of the GT61 (some of which are only very distantly related to this family). There are transcripts for 18 separate enzymes in family GT77 and two enzymes weakly related to GT90 Enzymes in these families are typically associated with plant cell wall biosynthesis and are predicted to be xylosyl- or galactosyl-transferases. Three potential GH43 xylosidases/galactosidases and a putative acetyl xylan esterase, which may be involved in degradation or tailoring of xylan structures, are also encoded in the transcriptome. Together this suggests that Euglena has the capability of synthesising xylose-containing polysaccharides and may either be able to degrade plant hemicellulose-related xylan or to recycle its own xylose-containing glycans. The physiological significance of these glycans is unknown, but it may be associated with the assembly and stability of the complex architecture of the flagella upon which Euglena depends for motility.

Glycoenzyme protein architecture. Many of the transcripts identified in the present study represent alternative splicing variants, information that would not be available from genome sequencing. For example, transcripts $\operatorname{lm} .75841$ and $\operatorname{lm} .75842$ share an identical N-terminus coding for a family GT1 glycosyltransferase, but the former has a C-terminal extension, encoding a peroxisomal protein, not present in the latter (Fig. 5A). The ratio of the transcripts of the long to short isoforms was approximately $11: 1$ in the light sample, but in the dark no short sequence variant is detectable. This suggests that in the light the enzyme activity is required in both subcellular locations, but in the dark it is not required in the cytosol. Euglena appears to make use of alternative splicing to control subcellular targeting of a single gene product, as has been seen for many enzymes ${ }^{60}$ including glycolytic enzymes in fungi ${ }^{61}$ and amino acid metabolic enzymes in plants. ${ }^{62}$

Whilst fusion of CBMs to other CAZYs is relatively common in nature, and contiguity of multiple glycoside hydrolase domains in a single protein is well known, it is much rarer to find glycosyltransferases in a protein containing other domains with carbohydrate binding or enzyme activity. ${ }^{63}$ Two transcripts 
A $\operatorname{lm} .75841$

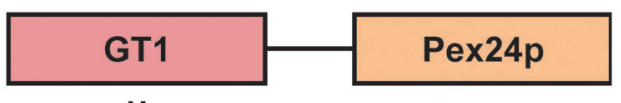

II

Im.75842

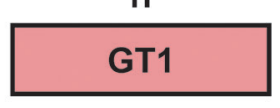

B

Im.71174

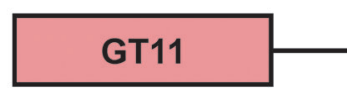

C

CBM57 dm.47703

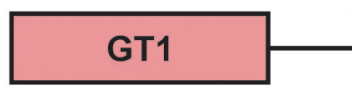

$\operatorname{Im} .25689$

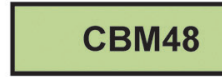

Im.29686

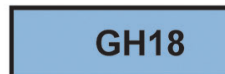

$\mathrm{dm} .80173$



GT15

GH78

Im.101413

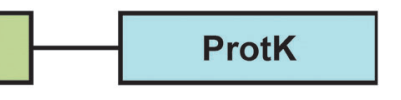

CBM18

\section{CBM63}

Fig. 5 Domain structures of Euglena carbohydrate-active enzymes. (A) Examples of splice variants in Euglena transcripts. Im.75841 (4.49) and Im.75842 (3.01) are identical for the first 354 amino acids, comprising a GT1 domain, but $\mathrm{Im} .75841$ has a further 421 amino acids, including a domain related to Pex $24 p$, an integral peroxisomal membrane protein. (B) Domain architecture of didomain CAZys encoded in the Euglena transcriptome. Im.71174 (0.90) encodes an N-terminal GT11 and a C-terminal GT15. dm.47703 (3.61) encodes an N-terminal GT1 and a C-terminal GH78. (C) Domain architectures of the four CBM containing sequences in Euglena. CBM48 is characterised as binding $\alpha-1,4$-glucans, and when associated with this protein kinase domain, as in Im.25689 (29.61), is the $\beta$-subunit of AMP-activated protein kinase. Im.29686 (15.02) contains a chitin-binding CBM18 and a chitin degrading GH18. dm.80173 (3.10) encodes a probable expansin and a cellulose directing CBM63. Im.101413 (0.56) encodes a CBM57 with no other protein domains. FPKM values in parentheses.

were identified in the Euglena transcriptome that encode proteins with more than one carbohydrate-active enzyme domain (Fig. 5B). The first protein ( $\mathrm{lm} .71174$ ) has a putative GT11 fucosyltransferase domain, whose active site does not contain the second arginine in the usual HxRRxD consensus motif, ${ }^{64}$ and a putative GT15 mannosyltransferase domain, which contains the nucleophile and a zwitterionic ion binding motif (Fig. S2, ESI $\dagger$ ). ${ }^{65}$ A second two-domain protein (dm.47703) appears to have a GT1 sugar transferase domain, most closely related to glucuronic acid transferases, ${ }^{66}$ linked to a C-terminal GH78 $\alpha$-rhamnosidase domain. ${ }^{67}$ This protein might conceivably be involved in cleaving rhamnose from a natural product and adding a glucuronic acid moiety, which is known to facilitate sub-cellular relocalisation and xenobiotic detoxification. ${ }^{68}$ Alternatively, it might be involved in editing glycan sequences and structures. Further work is required to assess these prospects.

Carbohydrate binding modules (CBMs) are typically found as part of the same polypeptide sequence as carbohydrateactive enzymes. ${ }^{69}$ There are 4 CBMs encoded in the Euglena transcriptome (Fig. 5C), compared to 126 in Arabidopsis and 40 in humans. ${ }^{40}$ The other sequenced Euglenozoa, Trypanosoma brucei and Leishmania braziliensis, only contain one CBM each, although these organisms live in stable animal hosts and so do not require complicated carbohydrate degradation mechanisms. The common conserved Euglenozoan CBM sits in family 48, typically associated with binding to glycogen, though Euglena do not themselves produce or use glycogen. This CBM is fused to the AMP-activated protein kinase beta subunit, $^{70}$ suggesting a phosphorylation-based regulatory role in carbohydrate metabolism for this bifunctional protein. Euglena also encodes a GH18 chitinase with a chitin-targeting CBM18, with a potential function in the degradation of extracellular chitin. A potential expansin for loosening plant cell wall glycan architectures, ${ }^{71}$ fused to a cellulose-binding CBM63, is also evident along with a single member of CBM57, a poorly characterised protein family thought to bind $N$-glycans ${ }^{72}$ (Fig. 5C).

Vitamin C. Ascorbic acid is the most important antioxidant in photosynthesising organisms, removing reactive oxygen species using ascorbate peroxidase. ${ }^{73}$ In Euglena this enzyme is localised in the cytosol, rather than the plastids, and has a unique dimeric form. ${ }^{74}$ In general, ascorbic acid is synthesised either via L-gulonolactone, as in animals, ${ }^{75}$ or by L-galactonate, as in plants ${ }^{76}$ and green algae (Fig. 6). ${ }^{77}$ Euglena has been proposed to contain a unique ascorbate biosynthesis pathway, via L-galactonolactone. $^{78}$ Radiotracer experiment show that, although Euglena can form vitamin C from L-gulonolactone, this L-galactonolactone pathway is dominant. ${ }^{79}$ More recently, the galacturonate reductase was identified, characterised and the N-terminal sequenced. ${ }^{80}$ The full-length transcript corresponding to this sequence is most closely related to malate dehydrogenase, highlighting the difficulty in correct functional assignment based solely on bioinformatics. In the transcriptome there is only one isoform of the aldonolactonase, which has been cloned previously and shown to have activity on both L-gulonate and L-galactonate. ${ }^{81}$ The remaining enzymes of ascorbate biosynthesis remain to be elucidated in this organism. In the transcriptome presented here candidates are present for every reaction in the biosynthesis of ascorbate, via $\mathrm{L}$-gulonolactone, L-galactose and L-galactonolactone. However several represent weak assignments, particularly as prediction of sugar-based substrates is notoriously difficult, and the major pathway for the synthesis of ascorbate seems to be via $\mathrm{L}$-galactonolactone. Transcriptome information presented here may facilitate the engineering of the various vitamin $\mathrm{C}$ pathways, either in Euglena or in other organisms.

\section{Small molecule redox regulators}

Given the genetic commitment to the production or watersoluble antioxidant vitamin $\mathrm{C}$ in Euglena, we were drawn to consider how much broader this commitment to handling redox stress might be. Euglena has long been known to produce high levels of vitamin E, ${ }^{82}$ a lipid-soluble antioxidant (Fig. 7). ${ }^{83}$ 
This vitamin is synthesised from tyrosine and phytol; genes encoding the key dioxygenase and homogentisate phytyl transferase are present in the transcriptome, along with strong candidates for the rest of the pathway (Fig. S3, ESI $\dagger$ ).

Whilst the tripeptide thiol glutathione ( $\gamma$-glutamyl-cysteinylglycine) plays a significant redox-modulating role in most eukaryotes and microorganisms, many bacteria and protozoa use additional unusual thiol compounds. ${ }^{84}$ These include mycothiol in actinobacteria, ${ }^{85}$ bacillithiol in some bacilli, ${ }^{86}$ and trypanothione and ovothiol in trypanosomatids. ${ }^{87}$ Independent reductases with exclusive activity towards either glutathione or trypanothione, have previously been purified from E. gracilis, ${ }^{88}$ although the occurrence of trypanothione has not been demonstrated in any Euglena. The conjugation of glutathione to spermidine to form trypanothione is carried out by either a two enzyme process (e.g. in Crithidia), with the initial conjugation of glutathione to spermidine by glutathionylspermidine synthase followed by addition of another glutathione by trypanothione synthase, ${ }^{89}$ or by a single bifunctional enzyme (e.g. in Trypanosoma). ${ }^{90}$ In the Euglena transcriptome, the biosynthetic pathways for glutathione and spermidine are present (Fig. S4, ESI $\dagger$ ), and there are two gene sequences which more closely match the trypanothione synthase than the glutathionylspermidine synthase of Crithidia, although they are most closely related to bacterial glutathionylspermidine synthases. It remains to be established whether these enzymes each carry out a single glutathione addition, or perform both conjugation steps.

With clear support for Euglena having a capacity to perform trypanothione biochemistry, we sought to demonstrate the presence of this thiol in Euglena extracts. HPLC analysis of bromobimane-derivatised cell extracts clearly show peaks for the ubiquitous glutathione and cysteine; there is also a small peak co-eluting with trypanothione, (Fig. S5, ESI $\dagger$ ). LC-MS revealed this fraction contained both trypanothione and a compound with a molecular weight 14 Da lower (Fig. S6, ESI $\dagger$ ). MS2 analysis revealed that this corresponds to a spermidine backbone that is one carbon shorter than is usual in trypanothione, which suggests the presence of the previously unreported nor-trypanothione (Fig. 7). Euglena is known to make the nor-spermine and nor-spermidine from 1,3-diaminopropane, which is thought to be derived from diaminobutyric acid. ${ }^{91}$ This would require some flexibility in the polyamine chain length in the trypanothione synthase, as is seen in T. cruzi, which makes homotrypanothione when supplied with exogenous cadavarine, one carbon longer than spermidine. ${ }^{92}$

The only known enzyme for the biosynthesis of ovothiol (Fig. 7) encodes a non-heme iron dioxygenase at the N-terminus

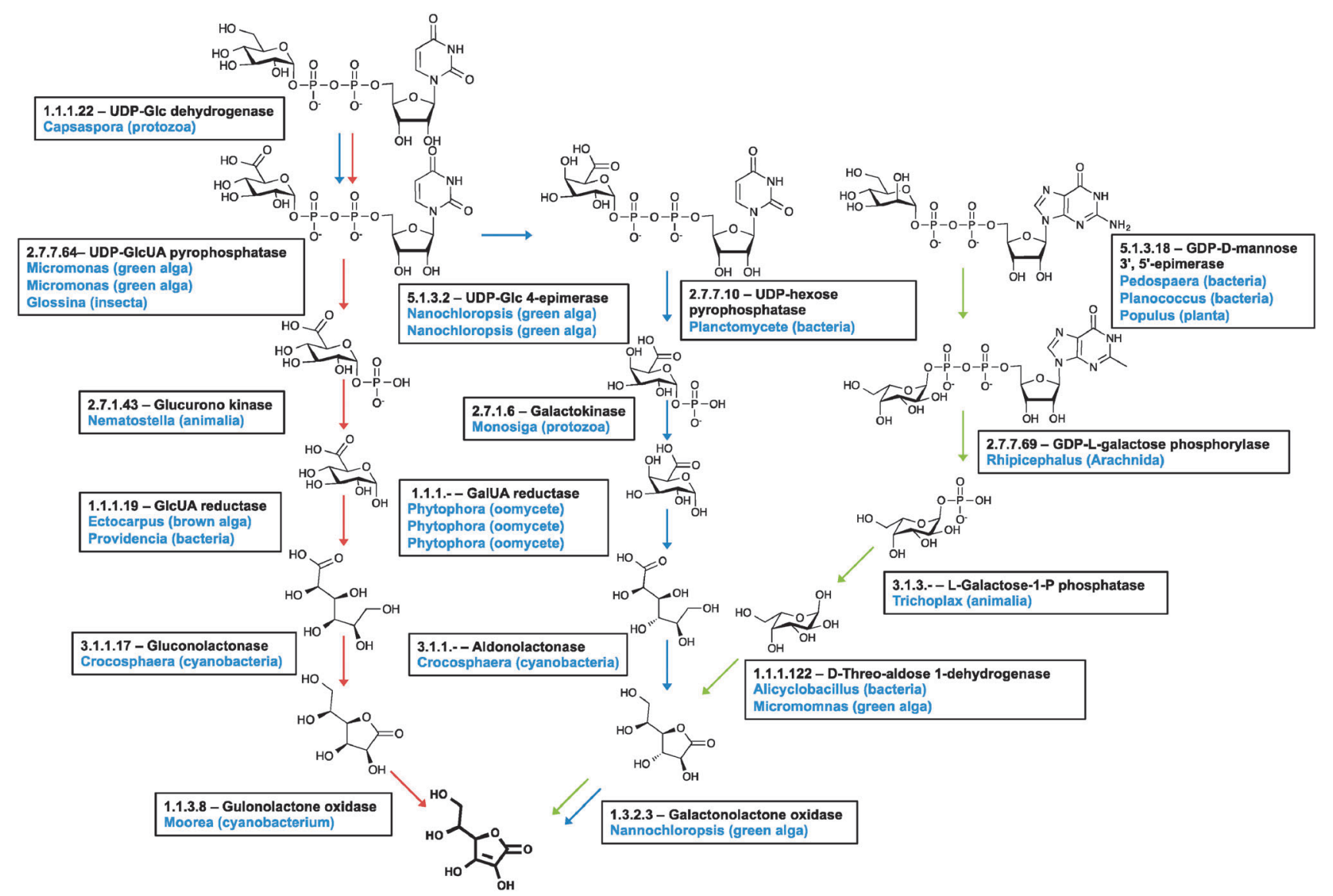

Fig. 6 Ascorbic acid biosynthesis. There are three pathways for the biosynthesis of ascorbate: the animal pathway (red arrows), the plant pathway (green arrows) and the Euglena pathway (blue arrows). Candidate genes in the Euglena transcriptome are indicated with the genus of the closest homologue to each isoform in blue. The Euglena aldonolactonase has been characterised in vitro and shown to act on both L-gulonate and L-galactonate. 
and an $\mathrm{N}$-methyl transferase at the C-terminus, capable of effecting oxidative $\mathrm{C}-\mathrm{S}$ bond formation, sulfoxidation and $N$-methylation (Fig. S4, ESI $\dagger$ ). ${ }^{93}$ In the Euglena transcriptome, there is one sequence related to the $\mathrm{N}$-terminus and one related to the C-terminus in both dark and light transcript sets, and a single transcript coding for both domains found only in the dark grown cells. A small peak eluting in the correct region of the HPLC, ${ }^{87}$ with consistent MS fragmentation, suggests that ovothiol is indeed present in Euglena (Fig. S5 and S6, ESI $\dagger$ ).

Given the prevalence of thiol biochemistry in Euglena, and the central role that ovothiol-related compounds (ergothioneine) have recently been shown to have in biosynthesis of the antibiotic lincomycin, ${ }^{94}$ we were drawn to evaluate the capacity of E. gracilis for coenzyme A/acyl carrier proteindependent processes, such as those that are often central to natural product biosynthesis. No polyketides or non-ribosomal peptides have been confirmed in Euglena to date, but there are transcripts apparent for the complex secondary metabolite synthases needed to make such compounds, as is evident for an increasing array of algae now that genome/transcriptome sequence data is becoming available. ${ }^{95}$

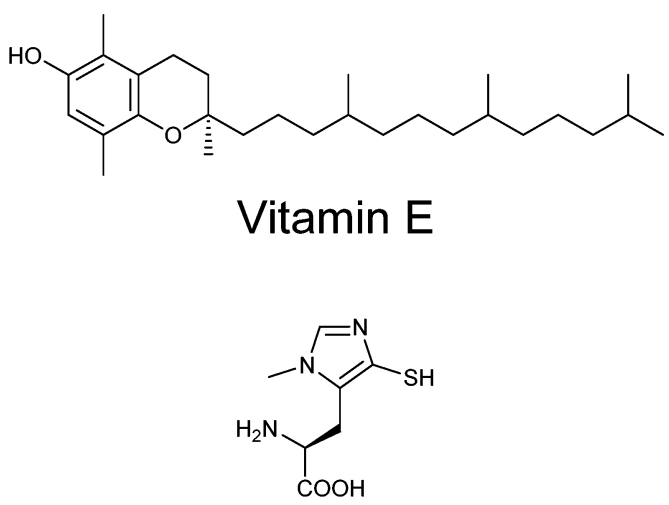

\section{Ovothiol}

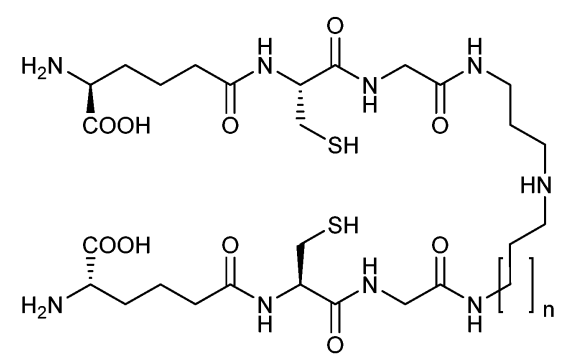

\section{Trypanothione $(\mathrm{n}=2)$ nor-Trypanothione $(\mathrm{n}=1)$}

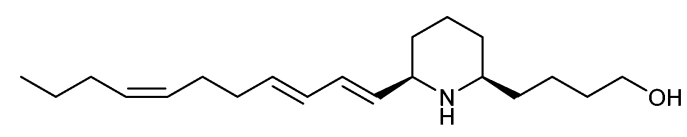

\section{Euglenophycin}

Fig. 7 Antioxidants and natural products produced by Euglena species.

\section{Polyketides}

Polyketides comprise a huge range of compounds, formed by repeated condensation of acetate units, followed by variable reduction and further elaboration. Broadly speaking polyketide synthases (PKSs) can be large multidomain proteins (type I) or composed of discrete proteins with individual functions (type II), although there are other architectures possible. ${ }^{96}$ Only one possible polyketide, the alkaloid euglenophycin (Fig. 7), has been isolated and characterised from a Euglena (Euglena sanguinea), based on its toxicity to fish. ${ }^{97}$ However, using the established isolation methods, ${ }^{98}$ we could find no evidence for the production of this compound by $E$. gracilis.

To identify polyketide synthases the proteome was searched for ketosynthases, the key catalytic domain, using BLASTP. ${ }^{99}$ Fourteen potential PKSs were identified as having this domain (Table S3, ESI $\dagger$ ): six sequences encode multiple domains indicative of type I PKSs; three sequences encode one catalytic domain and an acyl carrier protein domain; one sequence carries two catalytic domains; four sequences only encode individual domains. The latter may be true type II PKS modules, or fragments of type I caused by failure to assemble full length transcripts. They may also be enzymes with other functions that this search technique reveals, such as fatty acid synthases. The poor Kozak consensus and lack of upstream stop codons indicate these genes could encode fragments of longer proteins.

Attempts to predict the structures of the compounds synthesised by these putative Euglena PKS enzymes, based on domain architectures, using SBSPKS $^{100}$ and the PKS/NRPS Analysis Web-site, ${ }^{101}$ were not successful. This is probably due to the evolutionary distance from the bacterial and fungal species these pieces of software were designed to deal with. Analysis of the domain sequences of these enzymes using DELTA-BLAST, has allowed some assessment of the production line-like machinery and the products that could be made (Fig. 8). For example, in addition to a fully reducing PKS module, the largest polyketide synthase encoded in the Euglena transcriptome contains two enoyl hydratases and an HMGCoA synthase. As single domain proteins, these have been characterised in bacterial gene clusters as adding a $\beta$-methyl branch to polyketides such as bacillaene. ${ }^{102}$ This novel domain architecture suggests the formation of an alkane followed by addition of a $\beta$-methyl branch. Thus, although Euglena is not known to make polyketides, there is apparent capacity for the synthesis of complex natural products of this type.

\section{Non-ribosomal peptides}

Non-ribosomal peptide synthetases (NRPSs) are multi-domain proteins that join amino acids together to form small molecules with a diversity of function, including siderophores, such as enterobactin. ${ }^{103,104}$ No non-ribosomal peptides have been isolated from Euglenoids, but in the E. gracilis transcriptome, 19 putative NRPSs can be recognised based on the presence of the adenylation (A) domain and 16 based on the condensation (C) domain (Table S3, ESI $\dagger$ ). This search strategy reveals many sequences that are most closely related to enzymes involved in 


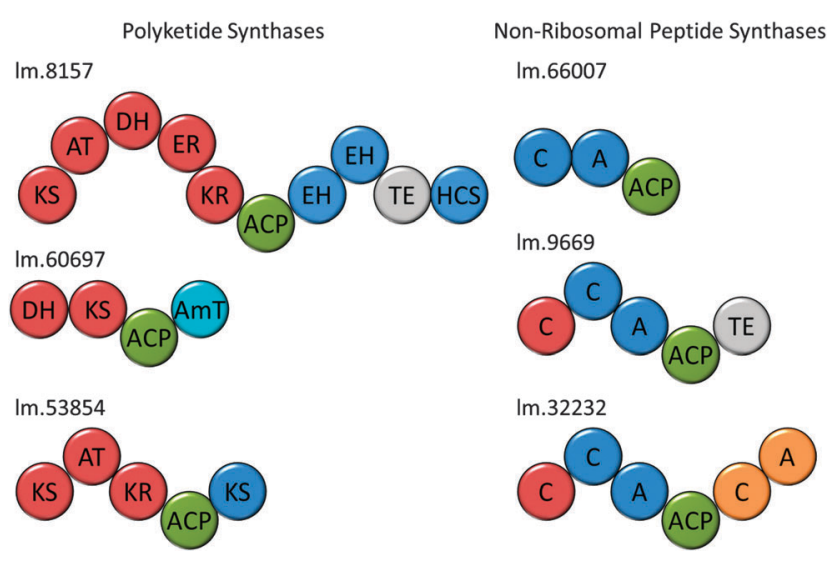

Fig. 8 Natural product synthases. Domain architectures of three candidate polyketide synthases and non-ribosomal peptide synthases from Euglena. Domains were identified using the Conserved Domain Database.

fatty acid biosynthesis and two transcripts for L-aminoadipatesemialdehyde dehydrogenase, involved in lysine biosynthesis. Five transcripts encode proteins with both an A and a $\mathrm{C}$ domain (Fig. 8), and the remainder have either only an A or only a $\mathrm{C}$ domain. Notably, three adenylation domain-encoding transcripts also have ankyrin domains, potentially involved in protein-protein interactions, ${ }^{105}$ which may imply formation of non-covalent assemblies of NRPS modules. The function prediction programs, SBSPKS ${ }^{100}$ and NRPS/PKS Analysis Website, ${ }^{101}$ were unable to predict structure from these sequences. However, given the ability of E. gracilis to actively uptake iron from growth medium (Fig. S7, ESI $\dagger$ ), it may be reasonable to speculate that Euglena use NRPSs to produce peptide-based siderophores, a well-known strategy amongst the bacteria. ${ }^{106}$

\section{Conclusions and outlook}

Euglena gracilis has been a mainstay of 20th century biology because of its ease of culture, large cell size and metabolic diversity. It is now evident that a combination of protozoan, animal, plant, fungal and prokaryotic genes contribute to its transcriptome, highlighting the evolutionary complexity of this unicellular alga. The wide range of metabolites in Euglena is a function of this evolutionary history, while sequences for enzymes involved in biosynthetic pathways not previously identified in Euglena suggests that we have barely scratched the surface of the metabolic potential of this class of organism.

Although its chloroplast genome, a prokaryote-like plasmid, was sequenced in 1993, ${ }^{107}$ Euglena has lagged behind as attention has largely focused on a limited number of model organisms. With the cost of nucleic acid sequencing decreasing rapidly, the opportunity to widen the repertoire of study organisms is considerable. The transcriptome dataset reported herein brings Euglena into the post genomic era and should facilitate the exploitation of this powerful bioresource, hopefully also stimulating wider consideration of microalgae as vehicles for natural products chemistry and synthetic biology.

\section{Experimental}

\section{E. gracilis cell culture}

Euglena gracilis var. saccharophila Klebs (strain 1224/7a) was obtained from the Culture Collection of Algae and Protozoa (http://www.ccap.ac.uk/).

High nutrient media. For culture in the dark, cells were grown in the recommended $1 \mathrm{X} \mathrm{EG}+1 \mathrm{X} \mathrm{JM}$ media (Euglena gracilis medium plus Jaworski's Medium, replacing "LabLemco" with Tryptone), supplemented with $15 \mathrm{~g} \mathrm{~L}^{-1}$ glucose, at $30{ }^{\circ} \mathrm{C}$ and shaken at $200 \mathrm{rpm}$ in the dark, for 7 days between sub-culturing. Dark grown cells were harvested by centrifugation at $800 \mathrm{~g}$ for $10 \mathrm{~min}$, with rapid decantation of the supernatant to avoid redistribution of the motile cells.

Low nutrient media. For culturing cells autotrophically, the media was adjusted to contain no amino acids or sugars as energy source. The medium consisted of $\mathrm{CaCl}_{2}\left(0.1 \mathrm{~g} \mathrm{~L}^{-1}\right)$, NaOAc. $\left(\mathrm{H}_{2} \mathrm{O}\right)_{3}\left(1 \mathrm{~g} \mathrm{~L} \mathrm{~L}^{-1}\right)$ and JM containing $15 \mathrm{~g} \mathrm{~L}^{-1}$ agar. Cultures were grown at $21{ }^{\circ} \mathrm{C}$ under ambient light and grew extremely slowly, taking 4 weeks between sub culturing. Light grown cells were collected by pipetting $1 \mathrm{ml}$ Milli-Q $\mathrm{H}_{2} \mathrm{O}$ to resuspend cells from the agar plate.

\section{RNA extraction, sequencing and bioinformatics}

Total RNA was isolated from $10^{6}$ dark and light grown cells using RNeasy Minikit (Qiagen) and stored at $-80{ }^{\circ} \mathrm{C}$. Source Bioscience (Nottingham, UK) then performed mRNA purification, library preparation and sequencing on an Illumina HiSeq 2000 platform. A total of 313205944 and 137689062 100-base, paired-end reads were obtained from the light- and dark-grown samples respectively. The light-grown sequence data, downsampled to 100 million pairs of reads, and the entire dataset of 68844531 read-pairs from the dark-grown sample were used for separate de novo assemblies using Trinity $^{30}$ version r2013-02-25, executed in parallel on two 256 GB cluster nodes. 233748 and 231176 raw assemblies were generated from light and dark respectively. Likely coding sequences were extracted from these reads using the Perl utility script supplied with the Trinity distribution, transcripts_to_best_scoring_ORFs.pl, producing 45126 and 47607 candidate ORFs of lengths greater than 100 amino acids. Putative coding sequences were combined and a non-redundant set of 32128 peptides produced using CD-HIT ${ }^{108}$ (v4.5.4) with an identity threshold of 0.95 and a word length of 5 . For functional annotation, the set was queried against the UniRef 100 protein database using BLASTP with an $E$-value threshold of $1 \times 10^{-10}$. Sequence identifiers of the best hits were harvested and used to programmatically collect from databases, via SOAP-based web services, GO terms and KEGG pathway objects, and also used to enumerate kingdom-level taxonomic classifications for the species of origin. Transcript levels for isoforms were estimated from the reads using the RSEM wrapper script supplied in the Trinity distribution to implement the RNA-Seq by Expectation Maximisation methods. ${ }^{109}$

\section{Annotation of carbohydrate-active enzymes (CAZys)}

Putative carbohydrate-active enzymes were identified and classified using the methods used for updating the carbohydrate-active 
enzymes database (CAZy; www.cazy.org) as described previously. ${ }^{40}$ Briefly, the translated protein sequences of Euglena were compared to the full-length sequences derived from CAZy using BLAST. ${ }^{110}$ The sequences that gave an $E$-value $<0.1$ were then subjected to a second BLAST search against a library made with the constitutive modules of glycoside hydrolases (GH), glycosyltransferases (GT), polysaccharide lyases (PL) and carbohydrate esterases (CE) and their associated carbohydrate-binding (CBM) modules. In parallel the sequences were subjected to a HMMer search using hidden Markov models built for each CAZy module family. ${ }^{111}$ A protein was considered reliably assigned when it was placed in the same family by the two methods. No particular $E$-value threshold was used as the $E$-value varies extensively with the length of the aligned sequences. Instead we relied on manual curation and examination of conserved features such as catalytic residues. Difficult cases were resolved by manual inspection of conserved features such as catalytic residues.

\section{Identification of thiols}

Cells grown in the high nutrient media, at $21{ }^{\circ} \mathrm{C}$ with ambient light, were collected by centrifugation at $13000 \mathrm{rpm}$, flash cooled in liquid nitrogen and stored at $-80{ }^{\circ} \mathrm{C}$ until analysis. $20 \mathrm{mg}$ of cells were extracted into $50 \%$ acetonitrile at $60{ }^{\circ} \mathrm{C}$ and the thiols were labelled with monobromobimane (Invitrogen) and separated on an ACE AR C18 $4.6 \times 250 \mathrm{~mm}, 5 \mu \mathrm{m}$ (HiChrom) by HPLC (JASCO) with fluorescence detection (JASCO FP2020 Plus) with excitation at $385 \mathrm{~nm}$ and emission at $460 \mathrm{~nm}$. The gradient used started from $0.225 \%$ aqueous acetic acid, $\mathrm{pH} 4.0$ to $100 \% 90 \%$ aqueous methanol over $50 \mathrm{~min}$, hold for $2 \mathrm{~min}$, reduced to $0 \%$ in $2 \mathrm{~min}$ and hold for $10 \mathrm{~min}$ with a flow rate of $1 \mathrm{ml} \mathrm{min}{ }^{-1}$. $^{85}$ Fluorescent peaks were collected and further analysed by LC-MS using a Surveyor HPLC attached to a DecaXPplus ion trap MS (Thermo). Separation was on a Kinetex XB-C18 $50 \times 2.1 \mathrm{~mm}, 2.6 \mu \mathrm{m}$ column (Phenomenex) running the following gradient of acetonitrile (B) versus $0.1 \%$ formic acid in water (A) at $300 \mu \mathrm{L} \mathrm{min}{ }^{-1}$ and $30{ }^{\circ} \mathrm{C}: 0 \mathrm{~min}, 2 \% \mathrm{~B} ; 10 \mathrm{~min}, 30 \% \mathrm{~B} ; 20 \mathrm{~min}$, 95\% B; $22 \mathrm{~min}, 95 \% \mathrm{~B} ; 22.5 \mathrm{~min}, 2 \% \mathrm{~B} ; 26 \mathrm{~min}, 2 \%$ B. Bimanelabelled thiols were detected by UV at $390 \mathrm{~nm}$, and positive electrospray MS. MS spectra were collected from $\mathrm{m} / \mathrm{z} 250-2000$ and MS2 spectra of the most abundant ions were collected at an isolation width of $\mathrm{m} / \mathrm{z} \quad 4.0$ and $35 \%$ collision energy. Spray chamber conditions were 50 units sheath gas, 5 units aux gas, $350{ }^{\circ} \mathrm{C}$ capillary temperature, and a spray voltage of $3.8 \mathrm{kV}$ using a steel needle kit.

\section{Accession codes}

Sequence reads were deposited in the Sequence Read Archive under submission number PRJEB10085.

\section{Acknowledgements}

These studies were supported by Basic Technology Grant GR/ S79268/02 from Research Councils UK, the UK BBSRC Institute Strategic Programme Grant on Understanding and Exploiting
Metabolism (MET) [BB/J004561/1], the John Innes Foundation and NIES/NSF [R01 ES21968-1 for PVZ]. We thank Tom Turner for assistance with RNA preparation and Mark Field for advice on protozoan biology.

\section{References}

1 C. Dobell and A. van Leeuwenhoek, Antony van Leeuwenhoek and his "Little animals": being some account of the father of protozoology and bacteriology and his multifarious discoveries in these disciplines; collected, translated, and edited, from his printed works, unpublished manuscripts, and contemporary records, Bale., 1932.

2 A. Van Leeuwenhoek, Philos. Trans. R. Soc. London, 1674, 9, 178-182.

3 J. Harris, Philos. Trans. R. Soc. London, 1695, 19, 254-259.

4 H. Takeyama, A. Kanamaru, Y. Yoshino, H. Kakuta, Y. Kawamura and T. Matsunaga, Biotechnol. Bioeng., 1997, 53, 185-190.

5 E. D. Korn, J. Lipid Res., 1964, 5, 352-362.

6 J. S. Rodríguez-Zavala, M. A. Ortiz-Cruz, G. MendozaHernández and R. Moreno-Sánchez, J. Appl. Microbiol., 2010, 109, 2160-2172.

7 Y. Kondo, A. Kato, H. Hojo, S. Nozoe, M. Takeuchi and K. Ochi, J. Pharmacobio-Dyn., 1992, 15, 617-621.

8 N. Koizumi, H. Sakagami, A. Utsumi, S. Fujinaga, M. Takeda, K. Asano, I. Sugawara, S. Ichikawa, H. Kondo, S. Mori, K. Miyatake, Y. Nakano, H. Nakashima, T. Murakami, N. Miyano and N. Yamamoto, Antiviral Res., 1993, 21, 1-14.

9 H. Inui, K. Miyatake, Y. Nakano and S. Kitaoka, FEBS Lett., 1982, 150, 89-93.

10 S. Tucci, R. Vacula, J. Krajcovic, P. Proksch and W. Martin, J. Eukaryotic Microbiol., 2010, 57, 63-69.

11 S. Dasgupta, J. Fang, S. S. Brake, S. T. Hasiotis and L. Zhang, Chem. Geol., 2012, 306-307, 139-145.

12 K. Y. Park, B.-R. Lim and K. Lee, Water Sci. Technol., 2009, 59, 2111-2116.

13 H. N. Guttman and H. B. Funk, Nature, 1967, 213, 103-104.

14 B. B. Anderson, J. Clin. Pathol., 1964, 17, 14-26.

15 R. Brayner, S. A. Dahoumane, C. Yéprémian, C. Djediat, M. 1. Meyer, A. Couté and F. Fiévet, Langmuir, 2010, 26, 6522-6528.

16 K. Ozasa, J. Lee, S. Song, M. Hara and M. Maeda, Appl. Soft Comput., 2013, 13, 527-538.

17 R. Brayner, T. Coradin, P. Beaunier, J.-M. Grenèche, C. Djediat, C. Yéprémian, A. Couté and F. Fiévet, Colloids Surf., B, 2012, 93, 20-23.

18 Y. Li, X. Tang, W. Song, L. Zhu, X. Liu, X. Yan, C. Jin and Q. Ren, IET Nanobiotechnol., 2015, 9, 19-26.

19 S. M. Strauch, P. Richter, M. Schuster and D. P. Häder, J. Plant Physiol., 2010, 167, 41-46.

20 D.-P. Häderi, A. Rosumi, J. Schäfer and R. Hemmersbach, J. Plant Physiol., 1995, 146, 474-480.

21 D. E. Buetow, The biology of Euglena: general biology and ultrastructure, Academic Press, 1968. 
22 D. E. Buetow, The biology of Euglena: biochemistry, Academic Press, 1968.

23 D. E. Buetow, The biology of Euglena: physiology, Academic Press, 1968.

24 D. E. Buetow, The biology of Euglena: subcellular biochemistry and molecular biology, Academic Press, 1989.

25 I. Ciugulea and R. E. Triemer, A Color Atlas of Photosynthetic Euglenoids, Michigan State University Press, 2010.

26 E. W. Linton, A. Karnkowska-Ishikawa, J. I. Kim, W. Shin, M. S. Bennett, J. Kwiatowski, B. Zakrys and R. E. Triemer, Protist, 2010, 161, 603-619.

27 m. i. p. An expanded discussion of these events will be published separately: E. C. O'Neill and R. A. Field.

28 P. Borst and R. Sabatini, Annu. Rev. Microbiol., 2008, 62, 235-251.

29 L.-H. Tessier, R. L. Chan, M. Keller, J.-H. Weil and P. Imbault, FEBS Lett., 1992, 304, 252-255.

30 H. Rismani-Yazdi, B. Z. Haznedaroglu, K. Bibby and J. Peccia, BMC Genomics, 2011, 12, 148.

31 P. J. Keeling, F. Burki, H. M. Wilcox, B. Allam, E. E. Allen, L. A. Amaral-Zettler, E. V. Armbrust, J. M. Archibald, A. K. Bharti, C. J. Bell, B. Beszteri, K. D. Bidle, C. T. Cameron, L. Campbell, D. A. Caron, R. A. Cattolico, J. L. Collier, K. Coyne, S. K. Davy, P. Deschamps, S. T. Dyhrman, B. Edvardsen, R. D. Gates, C. J. Gobler, S. J. Greenwood, S. M. Guida, J. L. Jacobi, K. S. Jakobsen, E. R. James, B. Jenkins, U. John, M. D. Johnson, A. R. Juhl, A. Kamp, L. A. Katz, R. Kiene, A. Kudryavtsev, B. S. Leander, S. Lin, C. Lovejoy, D. Lynn, A. Marchetti, G. McManus, A. M. Nedelcu, S. Menden-Deuer, C. Miceli, T. Mock, M. Montresor, M. A. Moran, S. Murray, G. Nadathur, S. Nagai, P. B. Ngam, B. Palenik, J. Pawlowski, G. Petroni, G. Piganeau, M. C. Posewitz, K. Rengefors, G. Romano, M. E. Rumpho, T. Rynearson, K. B. Schilling, D. C. Schroeder, A. G. B. Simpson, C. H. Slamovits, D. R. Smith, G. J. Smith, S. R. Smith, H. M. Sosik, P. Stief, E. Theriot, S. N. Twary, P. E. Umale, D. Vaulot, B. Wawrik, G. L. Wheeler, W. H. Wilson, Y. Xu, A. Zingone and A. Z. Worden, PLoS Biol., 2014, 12, e1001889.

32 M. G. Grabherr, B. J. Haas, M. Yassour, J. Z. Levin, D. A. Thompson, I. Amit, X. Adiconis, L. Fan, R. Raychowdhury, Q. Zeng, Z. Chen, E. Mauceli, N. Hacohen, A. Gnirke, N. Rhind, F. di Palma, B. W. Birren, C. Nusbaum, K. Lindblad-Toh, N. Friedman and A. Regev, Nat. Biotechnol., 2011, 29, 644-652.

33 E. L. Lasda and T. Blumenthal, Wiley Interdiscip. Rev.: RNA, 2011, 2, 417-434.

34 L. H. Tessier, M. Keller, R. L. Chan, R. Fournier, J. H. Weil and P. Imbault, EMBO J., 1991, 10, 2621-2625.

35 I. Coppens and P.-J. Courtoy, Exp. Parasitol., 1996, 82, 76-85.

36 H. K. Lichtenthaler, Annu. Rev. Plant Physiol. Plant Mol. Biol., 1999, 50, 47-65.

37 D. Kim, M. R. Filtz and P. J. Proteau, J. Nat. Prod., 2004, 67, 1067-1069.

38 T. L. Jahn, Manual of phycology: an introduction to the algae and their biology, Chronica Botanica Co., 1951.

39 D. R. Barras and B. A. Stone, Biochem. J., 1965, 97, 14-15.
40 B. L. Cantarel, P. M. Coutinho, C. Rancurel, T. Bernard, V. Lombard and B. Henrissat, Nucleic Acids Res., 2009, 37, D233-D238.

41 A. K. Monfils, R. E. Triemer and E. F. Bellairs, Phycologia, 2011, 50, 156-169.

42 D. Baumer, A. Preisfeld and H. G. Ruppel, J. Phycol., 2001, 37, 38-46.

43 J. Lomako, W. M. Lomako and W. J. Whelan, Biochim. Biophys. Acta, Gen. Subj., 2004, 1673, 45-55.

44 I. M. Saxena, R. M. Brown, M. Fevre, R. A. Geremia and B. Henrissat, J. Bacteriol., 1995, 177, 1419-1424.

45 D. R. Barras and B. A. Stone, Biochim. Biophys. Acta, 1969, 191, 329-341.

46 D. R. Barras and B. A. Stone, Biochim. Biophys. Acta, 1969, 191, 342-353.

47 E. C. O'Neill and R. A. Field, Carbohydr. Res., 2015, 403, 23-37. 48 S. H. Goldemberg, L. R. Maréchal and B. C. De Souza, J. Biol. Chem., 1966, 241, 45-50.

49 M. Kitaoka, T. Sasaki and H. Taniguchi, Arch. Biochem. Biophys., 1993, 304, 508-514.

50 Y. Yamamoto, D. Kawashima, A. Hashizume, M. Hisamatsu and N. Isono, Biosci., Biotechnol., Biochem., 2013, 77, 1949-1954.

51 M. Kitaoka, Y. Matsuoka, K. Mori, M. Nishimoto and K. Hayashi, Biosci., Biotechnol., Biochem., 2012, 76, 343-348.

52 T. Nihira, Y. Saito, M. Kitaoka, M. Nishimoto, K. I. Otsubo and H. Nakai, Carbohydr. Res., 2012, 361, 49-54.

53 S. A. Longwell and D. H. Dube, Curr. Opin. Chem. Biol., 2013, 17, 41-48.

54 P. Burda and M. Aebi, Biochim. Biophys. Acta, Gen. Subj., 1999, 1426, 239-257.

55 L. de la Canal and A. J. Parodi, Comp. Biochem. Physiol., Part B: Biochem. Mol. Biol., 1985, 81, 803-805.

56 J. Samuelson, S. Banerjee, P. Magnelli, J. Cui, D. J. Kelleher, R. Gilmore and P. W. Robbins, Proc. Natl. Acad. Sci. U. S. A., 2005, 102, 1548-1553.

57 M. Geetha-Habib and G. B. Bouck, J. Cell Biol., 1982, 93, 432-441.

58 G. B. Bouck, A. Rogalski and A. Valaitis, J. Cell Biol., 1978, 77, 805-826.

59 H. Ankel, E. Ankel, D. S. Feingold and J. S. Schutzba, Biochim. Biophys. Acta, 1967, 136, 172-175.

60 C. J. Danpure, Trends Cell Biol., 1995, 5, 230-238.

61 J. Freitag, J. Ast and M. Bolker, Nature, 2012, 485, 522-525.

62 J. S. Gebhardt, G. J. Wadsworth and B. F. Matthews, Plant Mol. Biol., 1998, 37, 99-108.

63 F. M. Medie, G. J. Davies, M. Drancourt and B. Henrissat, Nat. Rev. Microbiol., 2012, 10, 227-234.

64 T. Takahashi, Y. Ikeda, A. Tateishi, Y. Yamaguchi, M. Ishikawa and N. Taniguchi, Glycobiology, 2000, 10, 503-510.

65 Y. D. Lobsanov, P. A. Romero, B. Sleno, B. Yu, P. Yip, A. Herscovics and P. L. Howell, J. Biol. Chem., 2004, 279, 17921-17931.

66 A. M. Mulichak, W. Lu, H. C. Losey, C. T. Walsh and R. M. Garavito, Biochemistry, 2004, 43, 5170-5180.

67 Z. Cui, Y. Maruyama, B. Mikami, W. Hashimoto and K. Murata, J. Mol. Biol., 2007, 374, 384-398. 
68 R. H. Tukey and C. P. Strassburg, Annu. Rev. Pharmacol. Toxicol., 2000, 40, 581-616.

69 A. B. Boraston, D. N. Bolam, H. J. Gilbert and G. J. Davies, Biochem. J., 2004, 382, 769-781.

70 G. Gao, C. S. Fernandez, D. Stapleton, A. S. Auster, J. Widmer, J. R. B. Dyck, B. E. Kemp and L. A. Witters, J. Biol. Chem., 1996, 271, 8675-8681.

71 F. Kerff, A. Amoroso, R. Herman, E. Sauvage, S. Petrella, P. Filée, P. Charlier, B. Joris, A. Tabuchi, N. Nikolaidis and D. J. Cosgrove, Proc. Natl. Acad. Sci. U. S. A., 2008, 105, 16876-16881.

72 T. Schallus, C. Jaeckh, K. Fehér, A. S. Palma, Y. Liu, J. C. Simpson, M. Mackeen, G. Stier, T. J. Gibson, T. Feizi, T. Pieler and C. Muhle-Goll, Mol. Biol. Cell, 2008, 19, 3404-3414.

73 T. Ishikawa and S. Shigeoka, Biosci., Biotechnol., Biochem., 2008, 72, 1143-1154.

74 T. Ishikawa, N. Tajima, H. Nishikawa, Y. Gao, M. Rapolu, H. Shibata, Y. Sawa and S. Shigeoka, Biochem. J., 2010, 426, 125-134.

75 F. A. Isherwood, Y. T. Chen and L. W. Mapson, Biochem. J., 1954, 56, 1-15.

76 N. Smirnoff and G. L. Wheeler, Crit. Rev. Biochem. Mol. Biol., 2000, 35, 291-314.

77 E. I. Urzica, L. N. Adler, M. D. Page, C. L. Linster, M. A. Arbing, D. Casero, M. Pellegrini, S. S. Merchant and S. G. Clarke, J. Biol. Chem., 2012, 287, 14234-14245.

78 G. Wheeler, T. Ishikawa, V. Pornsaksit and N. Smirnoff, eLife, 2015, 4, 1-25.

79 S. Shigeoka, Y. Nakano and S. Kitaoka, J. Nutr. Sci. Vitaminol., 1979, 25, 299-307.

80 T. Ishikawa, I. Masumoto, N. Iwasa, H. Nishikawa, Y. Sawa, H. Shibata, A. Nakamura, Y. Yabuta and S. Shigeoka, Biosci. Biotechnol., Biochem., 2006, 70, 2720-2726.

81 T. Ishikawa, H. Nishikawa, Y. Gao, Y. Sawa, H. Shibata, Y. Yabuta, T. Maruta and S. Shigeoka, J. Biol. Chem., 2008, 283, 31133-31141.

82 J. C. Ogbonna, Appl. Microbiol. Biotechnol., 2009, 84, 217-225.

83 P. B. McCay and M. M. King, in Basic and clinical nutrition, Vitamin E: a comprehensive treatise, ed. L. J. Machlin, Marcel Dekker, Inc., 1980, vol. 1, pp. P289-P317.

84 R. L. Krauth-Siegel and A. E. Leroux, Antioxid. Redox Signaling, 2012, 17, 583-607.

85 T. Koledin, G. Newton and R. Fahey, Arch. Microbiol., 2002, 178, 331-337.

86 G. L. Newton, M. Rawat, J. J. La Clair, V. K. Jothivasan, T. Budiarto, C. J. Hamilton, A. Claiborne, J. D. Helmann and R. C. Fahey, Nat. Chem. Biol., 2009, 5, 625-627.

87 M. R. Ariyanayagam and A. H. Fairlamb, Mol. Biochem. Parasitol., 2001, 115, 189-198.

88 F. Montrichard, F. Le Guen, D. L. Laval-Martin and E. Davioud-Charvet, FEBS Lett., 1999, 442, 29-33.

89 E. Tetaud, F. Manai, M. P. Barrett, K. Nadeau, C. T. Walsh and A. H. Fairlamb, J. Biol. Chem., 1998, 273, 19383-19390.

90 M. Comini, U. Menge and L. Flohe, Biol. Chem., 2003, 384, 653-656.

91 V. R. Villanueva, R. C. Adlakha and R. Calvayrac, Phytochemistry, 1980, 19, 787-790.
92 K. J. Hunter, S. A. L. Quesne and A. H. Fairlamb, Eur. J. Biochem., 1994, 226, 1019-1027.

93 A. Braunshausen and F. P. Seebeck, J. Am. Chem. Soc., 2011, 133, 1757-1759.

94 Q. Zhao, M. Wang, D. Xu, Q. Zhang and W. Liu, Nature, 2015, 518, 115-119.

95 S. Sasso, G. Pohnert, M. Lohr, M. Mittag and C. Hertweck, FEMS Microbiol. Rev., 2012, 36, 761-785.

96 B. Shen, Y.-Q. Cheng, D. Christenson Steven, H. Jiang, J. Ju, H.-J. Kwon, S.-K. Lim, W. Liu, K. Nonaka, J.-W. Seo, C. Smith Wyatt, S. Standage, G.-L. Tang, S. Van Lanen and J. Zhang, Polyketides, American Chemical Society, 2007, ch. 11, vol. 955, pp. 154-166.

97 P. V. Zimba, P. D. Moeller, K. Beauchesne, H. E. Lane and R. E. Triemer, Toxicon, 2010, 55, 100-104.

98 D. B. Gutierrez, A. Rafalski, K. Beauchesne, P. D. Moeller, R. E. Triemer and P. V. Zimba, Toxins, 2013, 5, 1587-1596.

99 M. Johnson, I. Zaretskaya, Y. Raytselis, Y. Merezhuk, S. McGinnis and T. L. Madden, Nucleic Acids Res., 2008, 36, W5-W9.

100 S. Anand, M. V. R. Prasad, G. Yadav, N. Kumar, J. Shehara, M. Z. Ansari and D. Mohanty, Nucleic Acids Res., 2010, 38, W487-W496.

101 B. O. Bachmann and J. Ravel, in Complex enzymes in Microbial natural product biosynthesis, part A: overview articles and peptides, ed. D. A. Hopwood, 2009, vol. 458, pp. 181-217.

102 R. A. Butcher, F. C. Schroeder, M. A. Fischbach, P. D. Straight, R. Kolter, C. T. Walsh and J. Clardy, Proc. Natl. Acad. Sci. U. S. A., 2007, 104, 1506-1509.

103 C. T. Walsh, J. Liu, F. Rusnak and M. Sakaitani, Chem. Rev., 1990, 90, 1105-1129.

104 T. Noguchi, A. Shinohara, A. Nishizawa, M. Asayama, T. Nakano, M. Hasegawa, K.-I. Harada, T. Nishizawa and M. Shirai, J. Gen. Appl. Microbiol., 2009, 55, 111-123.

105 L. K. Mosavi, T. J. Cammett, D. C. Desrosiers and Z. Y. Peng, Protein Sci., 2004, 13, 1435-1448.

106 H. Drechsel and G. Jung, J. Pept. Sci., 1998, 4, 147-181.

107 R. B. Hallick, L. Hong, R. G. Drager, M. R. Favreau, A. Monfort, B. Orsat, A. Spielmann and E. Stutz, Nucleic Acids Res., 1993, 21, 3537-3544.

108 W. Li and A. Godzik, Bioinformatics, 2006, 22, 1658-1659.

109 E. Rebuffet, A. Groisillier, A. Thompson, A. Jeudy, T. Barbeyron, M. Czjzek and G. Michel, Environ. Microbiol., 2011, 13, 1253-1270.

110 S. F. Altschul, T. L. Madden, A. A. Schäffer, J. Zhang, Z. Zhang, W. Miller and D. J. Lipman, Nucleic Acids Res., 1997, 25, 3389-3402.

111 S. R. Eddy, Bioinformatics, 1998, 14, 755-763.

112 I. Letunic and P. Bork, Nucleic Acids Res., 2011, 39, W475-W478.

113 A. D. Tomos and D. H. Northcote, Biochem. J., 1978, 174, 283-290.

114 K. Vogel and A. A. Barber, J. Protozool., 1968, 15, 657-662.

115 L. R. Marechal and S. H. Goldemberg, Biochem. Biophys. Res. Commun., 1963, 13, 106-107. 